\title{
Sistem Informasi Peminjaman Dana Pada Koperasi Karyawan Dengan Pendekatan Sekuensial Linier
}

\author{
Nani Agustina ${ }^{1}$ Entin Sutinah ${ }^{2}$, Rizal Gustiar ${ }^{3}$ \\ ${ }^{1}$ Program Studi Sistem Informasi Akuntansi, Universitas Bina Sarana Informatika, Jl. Kamal Raya No.18 Ringroad Barat, Cengkareng Jakarta \\ Barat 11730, Indonesia \\ ${ }^{2}$ Program Studi Sistem Informasi, Universitas Bina Sarana Informatika, Jl. Kamal Raya No.18 Ringroad Barat, Cengkareng Jakarta Barat \\ 11730, Indonesia \\ ${ }^{3}$ Program Studi Sistem Informasi, STMIK Nusa Mandiri Jakarta, Jl. Damai No.8, Warung Jati Barat (Margasatwa), Jakarta Selatan, 12540, \\ Indonesia
}

\section{KEYWORDS}

Sistem Informasi, Peminjaman Dana, Koperasi

Karyawan, sekuensial linier

\section{CORRESPONDENCE}

Phone:

E-mail: entin.esh@bsi.ac.id

\section{INTRODUCTION}

Kebutuhan akan informasi yang berkembang dengan cepat menuntut sebuah kemajuan dalam sebuah teknologi dalam hal sistem informasi. Dengan menggunakan sebuah teknologi sistem informasi akan memudahkan dalam hal pekerjaan yang dilakukan oleh manusia. PT. XL Axiata adalah sebuah koperasi yang bergerak dibidang simpan pinjam dimana koperasi ini belum memanfaatkan sistem informasi sehingga penggolahan data belum tertata dengan rapi. Dalam kegiatan koperasi mengambil simpanan langsung memotong dari gaji setiap karyawan, dan apabila terdapat pinjaman juga pembayarannya otomatis dilakukan saat proses penggajian. Tetapi dalam proses pengajuan pinjaman dan persetujuan masih dilakukan secara bertahap menggunakan berkas dan butuh proses yang cukup lama.

Dalam membangun sebuah sistem koperasi yang ideal diharapakan dapat menyeimbangkan antara kebutuhan dana serta penyalurannya dana yang ada berupa bentuk pinjaman kepada karyawan dengan tujuan nantinya dapat meningkatkan kesejaterahan anggota.
Sistem merupakan kumpulan sub-sub sistem yang saling terkoneksi dan berkolaborasi untuk mencapai suatu tujuan tertentu denganmemproses input sehinggamenghasilkan output yang mempunyai nilai lebih dalam penggunaannya [1]. Data merupakan representasi dari fakta-fakta yang ada atau gambaran mengenai suatu objek atau kejadian yang pernah terjadi, tempat berkumpulnya data disebut dengan basis data [2]. Informasi adalah data yang telah dilakukan pengecekan dan diolah atau diinterpretasikan untuk nantinya akan digunakan dalam proses pengambilan keputusan. Sistem pengolahan informasi akan mengolah data menjadi informasi menjadi lebih berguna bagi yang menerimanya [3]. Sistem informasi merupakan gabungan dari empat bagian utama, keempat bagian tersebut mencakup perangkat lunak (software), perangkat keras (hardware), infrastruktur, dan sumber daya manusia (SDM) yang terlatih [4]. Teknologi informasi dapat digunakan dalam mengolah informasi pada suatu perusahaan, pengelolaan informasi sangat penting karena dapat menjadi dasar untuk mendapatkan keunggualn yang kompetitif [5].

Koperasi karyawan merupakan sebuah instansi yang berada lingkungan sebuah perusahaan. Saat ini proses pengelolaan data data yang ada di Koperasi karyawan [6]. Selama ini anggota harus mendatangi pengurus koperasi untuk menanyakan informasi jumlah simpanan dan saldo pinjaman serta mengurus 
hal-hal lainnya yang tentunya akan menyita banyak waktu dari para pengurus dan para anggota yang bersangkutan [7].

Koperasi adalah pengolahan data yang dahulu diolah secara manual kini menjadi sistem terkomputerisasi yang dapat memudahkan dalam proses pengolahan data. pengolahan data yang masih manual menggunakan microsoft excel yang di khawatirkan terjadi duplikasi atau inkonsistensi pada data, tidak ter update (pembaharuan) dengan baik dan tidak ada backup (cadangan) data, Sehingga dapat di simpulkan sistem yang berjalan saat ini belum optimal [8]. Koperasi Bina sejahtera masih mengalami kesulitan pengaksesan dan pengelolaan data simpan pinjam berupa simpanan, pinjaman, angsuran pinjaman dan sisa saldo anggotanya dikarenakan selama ini dilakukan dengan menggunakan buku secara cara manual dengan melihat catatan transaksidan ditambah adanya kemungkinan hilangnya formulir dan data tentang transaksi simpan pinjam koperasi. Dengan pengendalian risiko, koperasi harus didukung teknologi untuk membangun sistem informasi yang bersifat relevan, akurat, lengkap dan tepat waktu. Hal tersebut menjadi faktor pendukung untuk mencapai laba yang lebih maksimal. Selain itu juga diharapkan dapat meningkatkan profesionalitas independensi sebagai pelayanan masyarakat di bidang keuangan. [9].

Koperasi mengalami kesulitan apabila anggota ingin mengetahui jumlah saldo pinjaman yang didapat serta jumlah angsuran yang masih berjalan karena belum tersedianya sistem untuk pengecekan hal tersebut kendala lainnya data di simpan masih menggunakan file excel yang dirasa kurang mampu mengatasi masalah pencarian data anggota, data pinjaman dengan cepat lalu pengurus mencari satu persatu saldo pinjaman dan data pembayaran oleh anggota. [10].

Dari kutipan jurnal diatas memiliki persamaan yaitu sistem informasi koperasi pada suatu perusahan sangat di butuhkan untuk memudahkan pengurus koperasi dan anggota koperasi dalam administrasinya dan data, maka dari itu dapat menggunakan suatu sistem informasi koperasi berbasis web yang dapat memberikan kemudahan dalam pengaksesan, efektif dan akurat. Sehingga tidak terjadi kesalahan-kesalahan yang sifatnya mengganggu dalam proses peminjaman dan pembayaran iuran.

simpan pinjam yang masih menggunakan sistem manual akan menyebabkan kurang efektif dan efisiennya proses pengelolaan data.

\section{METHOD}

Metode penelitian ini dengan cara melakukan pengamatan ke koperasi PT. XL Axiata Jakarta pada bagian administrasi untuk melihat manajemen koperasi yang sedang berjalan. Setelah selesai tahap observasi dilanjutkan dengan tahap wawancara dengan ibu Vika sebagai staff admin yang sedang bertugas untuk mengetahui prosedur simpan pinjam secara detail, kendala dan masalah yang tidak didapat saat melakukan observasi. Tahap terakhir dilakukan dengan studi pustaka cara yang dilakukan dnegan mengumpulkan buku-buku referensi yang berkaitan dan system informasi koperasi berbasis web

Model SDLC (Software Development Life Cycle) air terjun (Waterfall) mempunyai istilah lain model sekuensi linier (Sequential liniar) atau dapat juga disebut alur hidup klasik (classic life cycle). Model waterfall menggunakan konsep pendekatan alur perangkat lunak secara sekuensial atau juga disebut konsep terurut dpada kegiatan yang dilakukan. dimulai dari tahap analisis, tahap desain, tahap pengodean, tahap pengujian, dan tahap pendukung (support) [11].

Pada metode ini tahap demi tahap yang dilalui harus menunggu selesainya tahap sebelumnya dan berjalan berurutan. Sebagai contoh sebelum melakukan tahap desain terlebih dahulu menyelesaikan tahap analisis. Berikut adalah gambar model waterfall/Skuensial Linier.

\section{Sistem/Rekayasa Informasi}

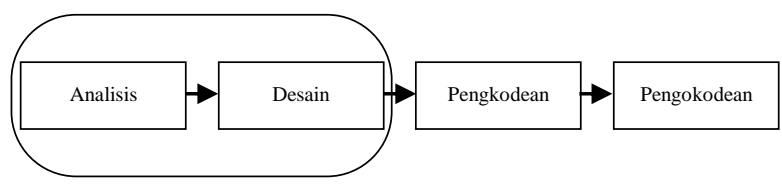

Sumber : [11]

Gambar 1. Ilustrasi Motode Waterfall/Skuensial Linier

Penjelasan dari tahap-tahap metode waterfall/Skuensial Linier, Analisis kebutuhan perangkat lunak, proses pengumpulan kebutuhan dilakukan secara intensif untuk mespesifikasikan kebutuhan perangkat lunak agar dapat dipahami perangkat lunak seperti apa yang dibutuhkan oleh user. Desain, dengan tahapan ini barufokus pada perancangan pembuatan program dengan membuat perangkat lunak termasuk struktur data dilanjutkanarsitektur perangkat lunak, representasi antarmuka, dan prosedur pengodean. Dalam pembuatan kode program, dengan ditranslasikan desain ke dalam program perangkat lunak. Hasil dari tahap ini adalah perangkat lunak harus sesuai dengan desain yang telah dibuat pada tahap desain. Pengujian, pengujian fokus pada perangkat lunak harus secara dari segi lojik (logic), fungsional dan memastikan bahwa semua bagian sudah diuji agar yang dihasilkan sesuai dengan yang diinginkan. Pendukung atau Pemeliharaan, tidak menutup kemungkinan sebuah perangkat lunak mengalami perubahan ketika sudah dikirimkan ke user. Perubahan bisa terjadi karena adanya kesalahan yang muncul tidak terdeteksi saat pengujian atau perangkat lunak harus beradabtasi dengan lingkungan baru.

Sistem informasi dalam penelitian ini dibuat kerangka pemikiran yang dapat menunjukan hasil dari kegiatan pembuatan sistem informasi peminjaman dana dengan memudahkan para anggota untuk mendapatkan inforamsi dan pihak admininistrasi juga dengan mudah dalam mengelolah. Semua kegiatan dapat diakses melalui website tetapi dilakukan dengan berbasis intranet.

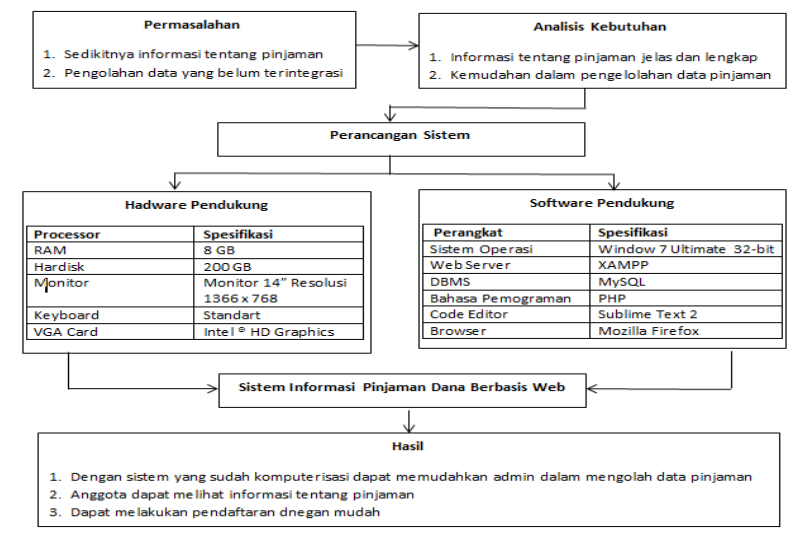

Gambar 2. Kerangka Pemikiran Sistem Informasi Pinjaman Dana Berbasis Website

Sesuai dengan kerangka penelitian yang telah ada, tahap-tahap penelitian dilakukan secara berurutan mulai dari tahap permasalahan, perancangan sistem, pembuatan sistem informasi berbasis website dan hasil akhir yang diperoleh dari penelitian.. 


\section{RESULTS AND DISCUSSION}

\section{Permasalahan}

Seperti pada contoh koperasi simpan pinjam di PT XL Axiata yang dimana belum memanfaatkan sistem informasi sehingga pengolahan datanya belum tertata rapi seperti pendaftaran untuk menjadi anggota masih menggunakan form dikertas dan anggota melakukan pinjaman, anggota juga mengalami minim nya informasi tentang angsuran pinjaman dan juga masih menggunakan kertas sehingga memakan biaya dan waktu, apalagi saat pembuatan laporan bulanan belum tertata rapi karna masih menggunakan kertas dan kertas laporan setiap tahunnya bertumpuk bersiko memakan tempat dan pencarian data nya juga memakan waktu,

\section{Perancangan Sistem}

Tahap awal yang dilakukan dengan melakukan pengecekan dokumen-dokumen yang berkaitan dengan pinjaman adalah form peminjaman. Untuk merancang sistem informasi koperasi simpan pinjam di PT XL Axiata secara sistem dimulai dari perancangan entity relationship diagram (ERD), usecase diagram, activity diagram, Component Diagramdan Deployment Diagram. Perancangan entity relationship diagram (ERD) pada sistem informasi sebagaimana pada gambar 3. Hasil dari ERD tersebut selanjutnya untuk merancang spesifikasi tabel, pada sistem informasi koperasi simpan pinjam di PT XL Axiata dihasilkan 28 (dua puluh delapan) tabel dan 11 (sebelas) tabel yang berelasi. Gambar 3 merupakan perancangan entity relationship diagram $(E R D)$ sistem informasi peminjaman dana berbasis website pada koperasi simpan pinjam di PT XL Axiata.

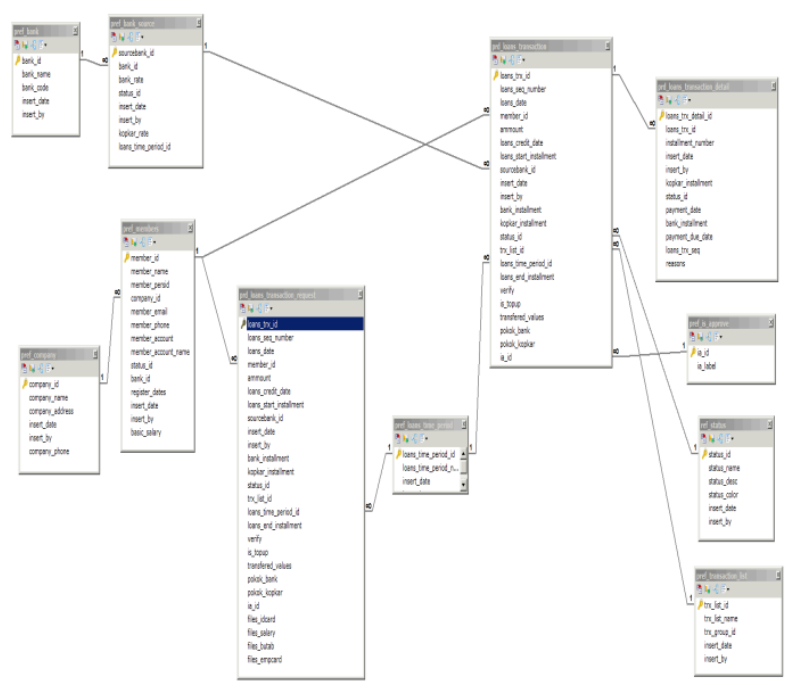

Gambar 3.ERD Sistem Informasi Pinjaman Dana Berbasis Website

Usecase diagram sistem pinjaman dana berbasis website pada PT XL Axiata terdiri dari 4 aktor diantaranya: anggota, admin, bendahara, kepala koperasi. Dengan tampilan usecase berikut :

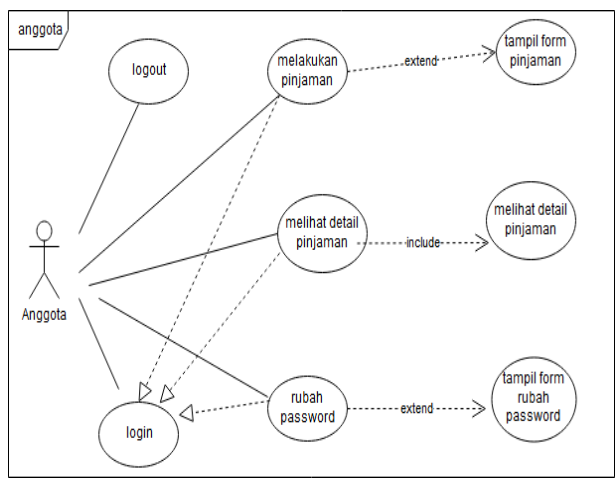

Gambar 4.Usecase Diagram Anggota informasi peminjaman dana berbasis website

Perancangan ini anggota diberikan hal akses untuk melakukan login dan dapat secara langsung melakukan pinjaman dan dapat melihat angsuran pinjamannya. Apabila lupa password, anggota juga dapat melakukan reset password sendiri.

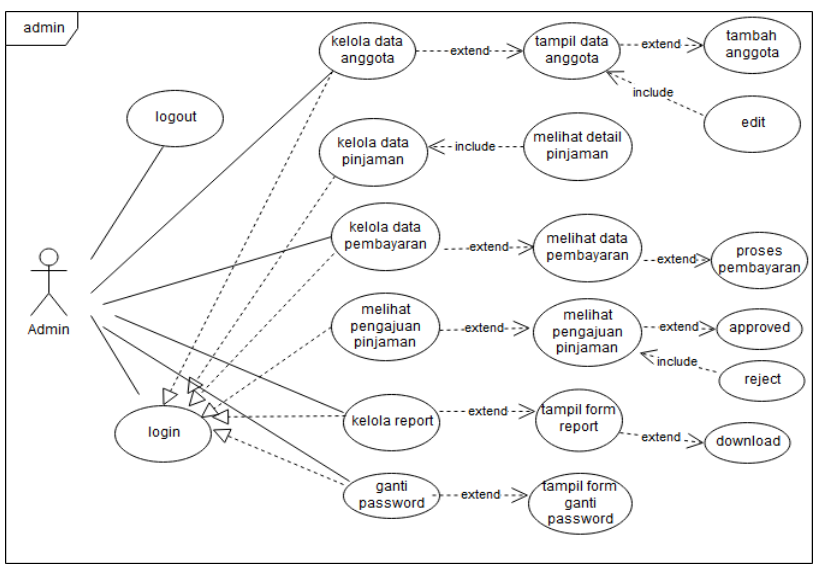

Gambar 5. Usecase Diagram Administrasi sistem informasi peminjaman dana berbasis website

Admin memiliki akses untuk dapat mengolah sistem secara keseluruhan dimulai dari dapat membuat iuser untuk anggota baru, dapat melihat data pinjaman, mengelola data anggota, melihat pengajuan pinjaman serta besarnya dana pinjaman, pemasukan dana serta pengeluaran dana, keputusan dalam pinjam, dana pemasukan sampai dengan membuat report untuk kepala koperasi

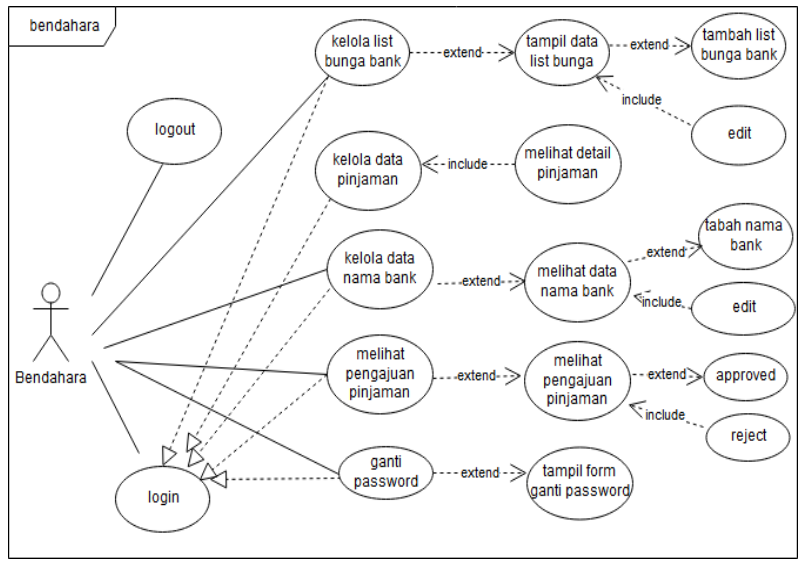

Gambar 6.Usecase Diagram Bendahara informasi peminjaman dana berbasis website 
Bendahara dapat merubah password, melihat dana pengeluaran dan pemasukan, dapat melihat anggota yang meminjam, melihat data angsuran cicilan anggota dan besarnya cicilan anggota serta menyetujui pinjaman atau reject pinjaman anggota, mengatur rate bunga dan mengatur list bank yang bekerja sama.

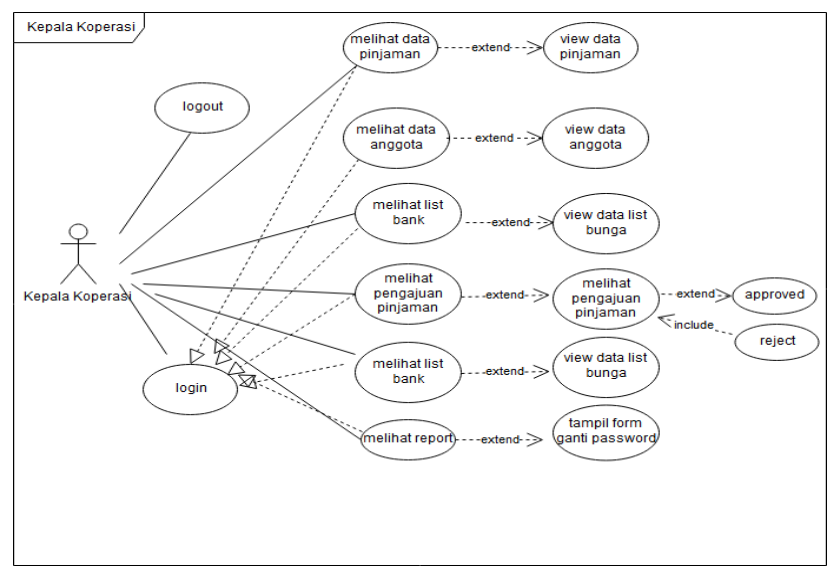

Gambar 7. Usecase Diagram Kepala Koperasi sistem informasi peminjaman dana berbasis website

Kepala koperasi dapat melakukan approved dan reject pinjaman baru, dapat melihat data anggota, melihat data pinjaman, melihat list bunga bank, melihat list bunga nama bank.

Interaksi antara aktor dengan sistem dijelaskan dalam activity diagram sebagaimana gambar 8 .

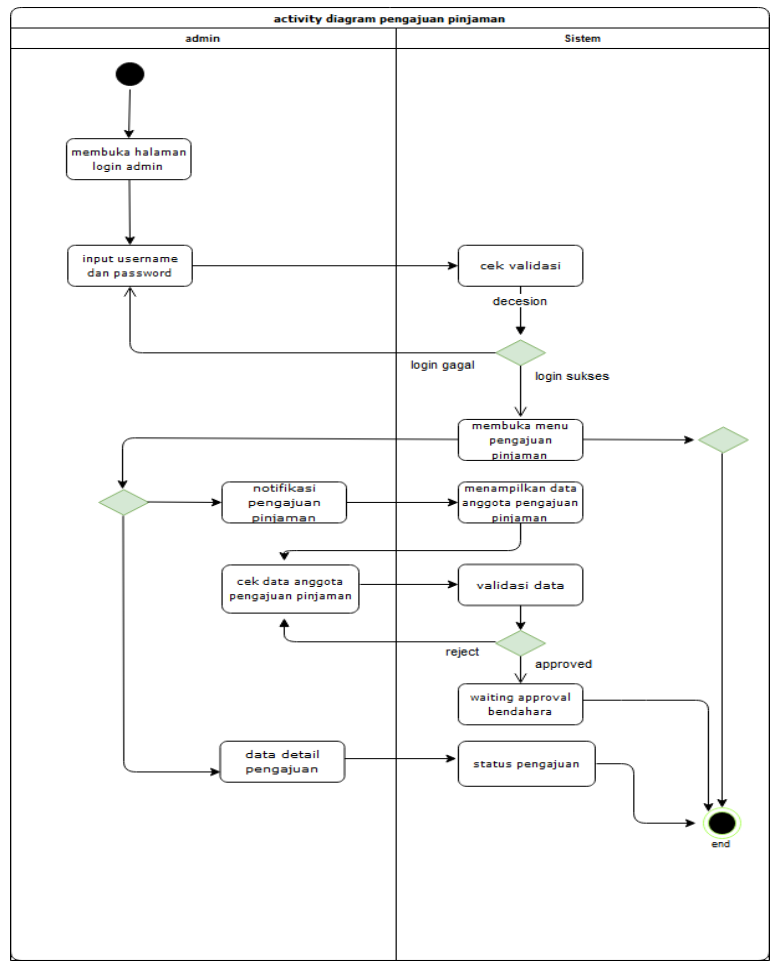

Gambar 8.Aktivity Diagram Pengajuan Pinjaman sistem informasi peminjaman dana berbasis website

Tugas dari admin salah satunya melakukan penginputan pengajuan pinjaman yang dilakukan oleh anggota melalui sistem kemudian apabila pengajuan sudah dibuat nanti muncul pada 108 Nani Agustina form pengajuan untuk menunggu status pengajuan ditolak atau disetujui

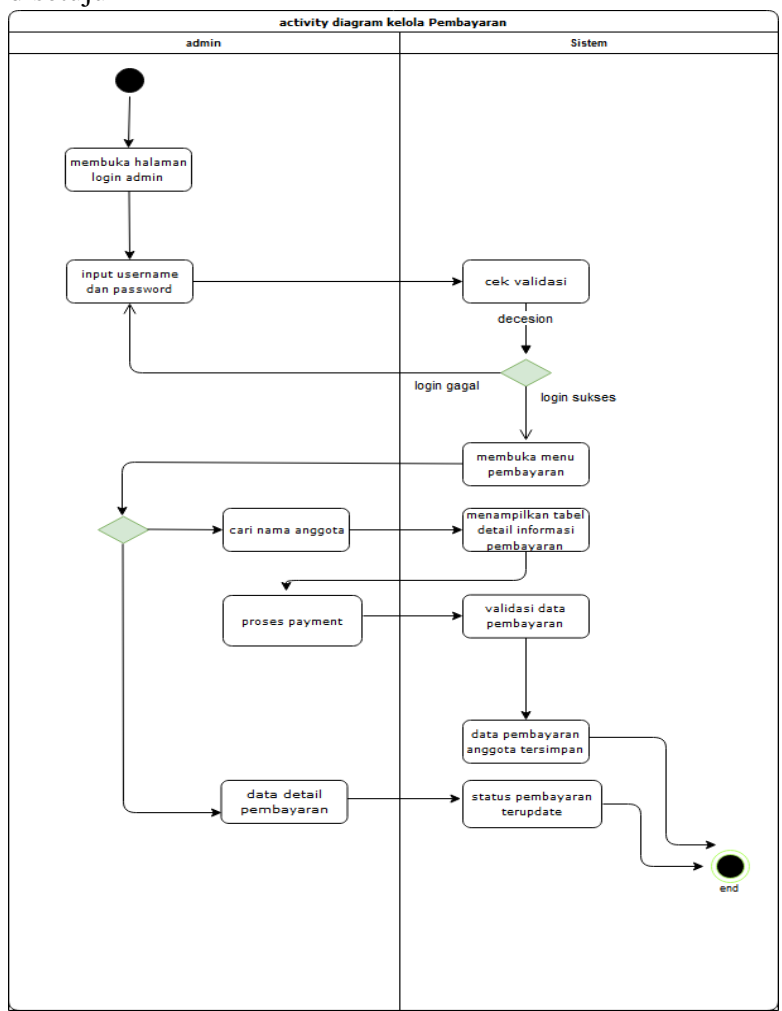

Gambar 9. Aktivity Diagram Pengajuan Kelola Pembayarn sistem informasi peminjaman dana berbasis website.

Bagian dari Administasi bertugas mengelola pembayaran juga yang dilakukan oleh anggota. Apabila sudah diterima pembayarannya maka status di anggota untuk angsurannya berkurang dan data pembayaran terupdate.

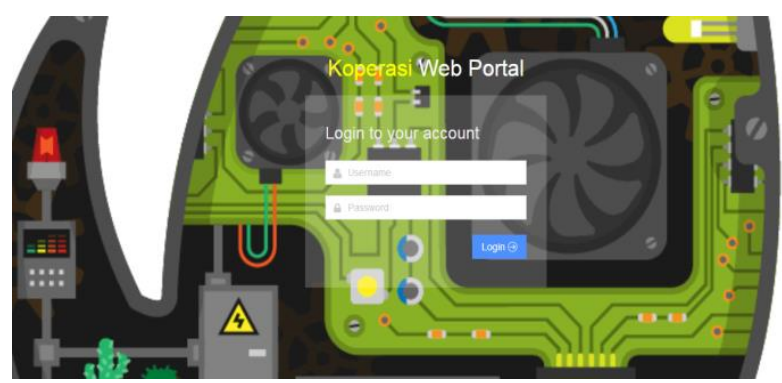

Gambar 10.Tampilan login user.

Berdasarkan rancangan login pada gambar.10 maka dapat dijelaskan bahwa rancangan login merupakan tahap untuk masuk ke menu utama.Dalam login pemakai, username dan password harus dimasukan dengan benar untuk masuk ke dalam menu utama. Jika username dan password tidak dimasukan dengan benar maka user tidak dapat masuk ke dalam menu utama. 


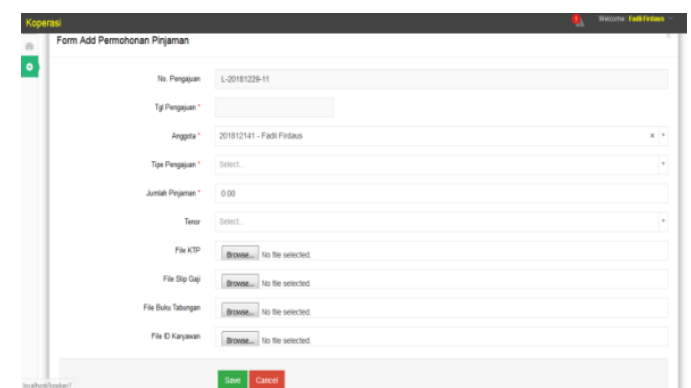

Gambar 11. Tampilan permohonan pinjamansistem informasi peminjaman dana berbasis website

Berdasarkan rancangan transaksi penyimpanan pada gambar 11, maka dapat dijelaskan bahwa rancangan transaksi permohonan pinjaman digunakan untuk menambahkan proses transaksi permohonan pinjaman. Jika data yang dimasukan benar maka akan disimpan ke dalam database.

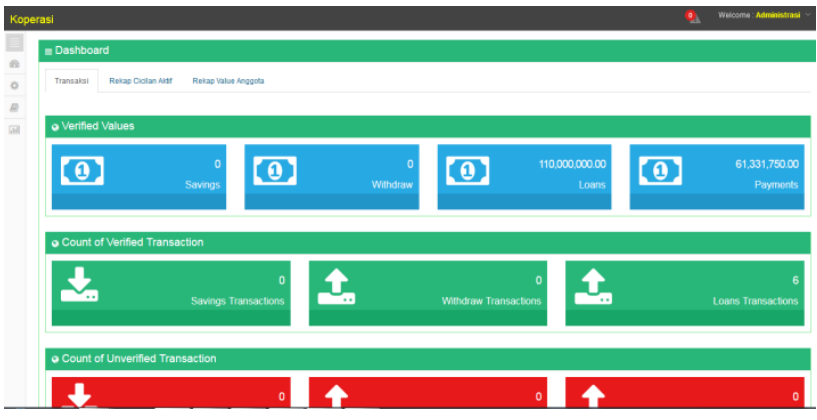

Gambar 12.Tampilan menu utama admin sistem informasi peminjaman dana berbasis website.

Tampilan menu utama admin pada menu utama pada gambar 12 maka dapat dijelaskan bahwa rancangan menu utama merupakan tahap untuk masuk dan berhubungan langsung dengan aplikasi yang telah tersedia untuk melakukan pengolahan data pada sistem.

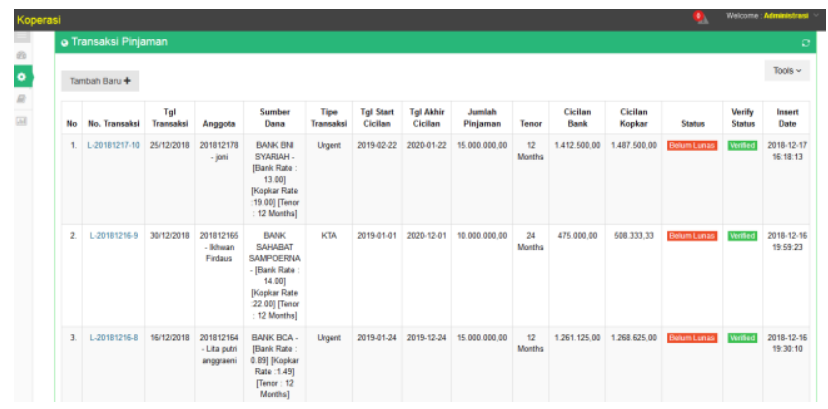

Gambar 13. Tampilan Transaksi Pinjaman Admin sistem informasi peminjaman dana berbasis website

Menu tersebut digunakan pleh bendahara yang digunakan untuk melakukan approved dan reject pinjaman baru yang diajukan oleh anggota.
Tabel 1. Hasil Pengujian Black Box Testing Form Pengajuan Pinjaman

\begin{tabular}{|c|c|c|c|c|c|}
\hline $\begin{array}{l}N \\
0\end{array}$ & $\begin{array}{l}\text { Skenario } \\
\text { Pengujuan }\end{array}$ & Test Case & $\begin{array}{l}\text { Hasil } \\
\text { yang } \\
\text { diharap } \\
\text { kan }\end{array}$ & $\begin{array}{l}\text { Hasil } \\
\text { pengu } \\
\text { jian }\end{array}$ & $\begin{array}{l}\text { Kesimp } \\
\text { ulan }\end{array}$ \\
\hline 1 & $\begin{array}{l}\text { Mengoson } \\
\text { gkan } \\
\text { semua } \\
\text { kolom } \\
\text { pengajuan } \\
\text { pinjaman }\end{array}$ & $\begin{array}{l}\text { Tanggal } \\
\text { pengajuan : } \\
\text { (kosong) } \\
\text { Tipe } \\
\text { pengajuan : } \\
\text { (kosong) } \\
\text { Jumlah } \\
\text { pinjaman:(k } \\
\text { osong) } \\
\text { Tenor : } \\
\text { (kosong) } \\
\text { File ktp : } \\
\text { (kosong) } \\
\text { File slip gaji } \\
\text { : (kosong) } \\
\text { File buku } \\
\text { tabungan : } \\
\text { (kosong) } \\
\text { File id } \\
\text { karyawan : } \\
\text { (kosong) }\end{array}$ & $\begin{array}{l}\text { Sistem } \\
\text { akan } \\
\text { menola } \\
\mathrm{k} \text { form } \\
\text { pengaju } \\
\text { an } \\
\text { pinjama } \\
\mathrm{n} \\
\text { dengan } \\
\text { notif } \\
\text { lengkap } \\
\text { i data }\end{array}$ & $\begin{array}{l}\text { Sesuai } \\
\text { harapa } \\
\mathrm{n}\end{array}$ & Valid \\
\hline 2 & $\begin{array}{l}\text { Mengkoso } \\
\text { ngkan } \\
\text { salah satu } \\
\text { pada form } \\
\text { pengajuan } \\
\text { pinjaman }\end{array}$ & $\begin{array}{l}\text { Tanggal } \\
\text { pengajuan : } \\
\text { (kosong) } \\
\text { Tipe } \\
\text { pengajuan : } \\
\text { (di isi) } \\
\text { Jumlah } \\
\text { pinjaman:(di } \\
\text { isi) } \\
\text { Tenor : } \\
\text { (diisi) } \\
\text { File ktp : } \\
\text { (diisi) } \\
\text { File slip gaji } \\
\text { : (diisi) } \\
\text { File buku } \\
\text { tabungan : } \\
\text { (diisi) } \\
\text { File id } \\
\text { karyawan : } \\
\text { (diisi) }\end{array}$ & $\begin{array}{l}\text { Sistem } \\
\text { akan } \\
\text { menola } \\
\mathrm{k} \text { form } \\
\text { pengaju } \\
\text { an } \\
\text { pinjama } \\
\mathrm{n} \\
\text { dengan } \\
\text { notif } \\
\text { please } \\
\text { input } \\
\text { tanggal } \\
\text { peminja } \\
\text { man }\end{array}$ & $\begin{array}{l}\text { Sesuai } \\
\text { harapa } \\
n\end{array}$ & Valid \\
\hline 3 & $\begin{array}{l}\text { Mengisi } \\
\text { semua } \\
\text { pada form } \\
\text { pengajuan } \\
\text { pinjaman }\end{array}$ & $\begin{array}{l}\text { Tanggal } \\
\text { pengajuan : } \\
\text { (diisi) } \\
\text { Tipe } \\
\text { pengajuan : } \\
\text { (di isi) } \\
\text { Jumlah } \\
\text { pinjaman:(di } \\
\text { isi) } \\
\text { Tenor : } \\
\text { (diisi) } \\
\text { File ktp : }\end{array}$ & $\begin{array}{l}\text { Sistem } \\
\text { akan } \\
\text { meneri } \\
\text { ma } \\
\text { form } \\
\text { pengaju } \\
\text { an } \\
\text { pinjama } \\
\text { n dan } \\
\text { sukses } \\
\text { mengaj } \\
\text { ukan }\end{array}$ & $\begin{array}{l}\text { Sesuai } \\
\text { harapa } \\
n\end{array}$ & Valid \\
\hline
\end{tabular}




\begin{tabular}{|c|c|c|c|c|c|}
\hline $\begin{array}{l}\mathrm{N} \\
\mathrm{o}\end{array}$ & $\begin{array}{l}\text { Skenario } \\
\text { Pengujuan }\end{array}$ & Test Case & $\begin{array}{l}\text { Hasil } \\
\text { yang } \\
\text { diharap } \\
\text { kan }\end{array}$ & $\begin{array}{l}\text { Hasil } \\
\text { pengu } \\
\text { jian }\end{array}$ & $\begin{array}{l}\text { Kesimp } \\
\text { ulan }\end{array}$ \\
\hline & & (diisi) & pinjama & & \\
\hline & & $\begin{array}{l}\text { File slip gaji } \\
: \text { (diisi) }\end{array}$ & $\mathrm{n}$ & & \\
\hline & & File buku & & & \\
\hline & & tabungan : & & & \\
\hline & & (diisi) & & & \\
\hline & & File id & & & \\
\hline & & karyawan : & & & \\
\hline & & (diisi) & & & \\
\hline
\end{tabular}

\section{CONCLUSIONS}

Berdasarkan hasil penelitian pada koperasi simpan pinjam di PT XL Axiata maka dihasilkan Sitem INformasi Simpan Pinjam Berbasis Website sehingga dapat menyelesaikan masalah yaitu dengan adanya sistem antara lain 1) Sistem informasi koperasi ini akan mempermudah para staff koperasi dalam input data anggota baru, melihat cicilan anggota, melihat data pinjaman, dan penyimpanan arsip atau pun report koperasi tanpa harus khawatir tersebut rusak atau hilang 2) Adanyasistem ini mempermudah karyawan melakukan pinjaman dana, melihat jumlah cicilan dan jumlah angsuran cicilan. 3) Meningkatkan kinerja dan mempermudah para staff koperasi dalam mencari data yang dibutuhkan tanpa mencari lewat media kertas yang sebelumnya di catat. Selanjutnya peneliti akan memberikan saran yang akan digunakan untuk penelitian selanjutnya. Pada aspek sistem dan program, peneliti memberikan saran 1) Memperbaruhi secara rutin antivirus. 2) Database yang digunakan perlu diamankan secara berkala agar data tetap aman ketika computer bermasalah. Pada aspel peneliti selanjutnya, 1) Diharapkan adanya fitur pembayaran cicilan yang langsung terhubung dari rekening bank. 2) Dibuatnya notifikasi ke email apabila sudah melakukan pembayaran

\section{REFERENCES}

[1] R. Taufiq, Sistem Informasi Manajemen; Konsep Dasar, Anlisis dan Metode Pengembangan. Yogyakarta: Graha Ilmu, 2013.

[2] Fathansyah, Basis Data. Bandung: Informatika Bandung, 2012.

[3] T. Sutabri, Analisa Sistem Informasi. Yogyakarta: Andi Ofiset, 2012.

[4] I. P. A. E. Pratama, Sistem Informasi dan Implementasinya. Bandung: informatika Bandung, 2014.

[5] Tukino, "Rancang Bangun Aplikasi e-CRM Alfamart Batam Dengan Metode Extreme," InfoTekJar J. Nas. Inform. dan Teknol. Jar., vol. 2, no. 2, pp. 21-31, 2019.

[6] D. Puspitasari, "Rancang Bangun Sistem Informasi Koperasi Simpan Pinjam Karyawan Berbasis Web," $J$. Pilar Nusa Mandiri, vol. XI, no. 2, pp. 186-196, 2015.

[7] H. K. Wati and K. Siahaan, "Analisis Dan Perancangan Sistem Informasi Koperasi Simpan Pinjam Berbasis Web Pada Mts Negeri Talang Bakung Kota Jambi," J. Manaj. Sist. Inf., vol. 2, no. 3, pp. 641-660, 2017.

[8] M. Nursaman, K. A. Intan, and F. Matondang,
"Aplikasi Sistem Informasi Koperasi Karyawan Pada Pt.Surya Siam Keramik," Semin. Nas. Teknol. Inf. dan Multimed., p. 2.10-31-2.10-36, 2018.

[9] O. Sarwengga, J. Abdillah, and I. Yuniar, "Sistem Informasi Akuntansi Simpan Pinjam Berbasis Web (Studi Kasus Pada Koperasi Bina Sejahtera Bandung)," J. Rekayasa Sist. Ind., vol. 1, no. 2, pp. 28-33, 2014.

[10] J. Abdilla and O. B. S, "Aplikasi Sistem Informasi Simpan Pinjam Berbasis Web Pada Koperasi Spbni Syariah,” J. LPKIA, vol. 2, no. 1, pp. 13-19, 2013.

[11] R. A. Sukamto and M. Shalahuddin, Rekayasa Perangkat Lunak Tersrtuktur dan Berbasis Objek. Bandung: Informatika Bandung, 2013.

\section{AUTHOR(S)BIOGRAPHY}

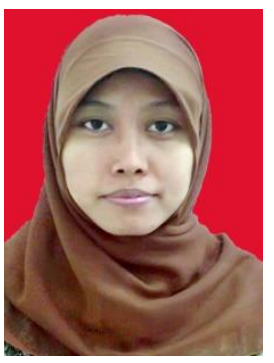

\section{Nani Agustina}

Tahun 2009 program S1 STMIK Nusa Mandiri, Tahun 2011 lulus S2 pada Pasca Sarjana Nusa Mandiri Jakarta, dan berkerja menjadi staff pengajar pada Universitas Bina Sarana Informatika dari tahun 2008 sampai dengan sekarang Fakultas Teknologi Informasi.

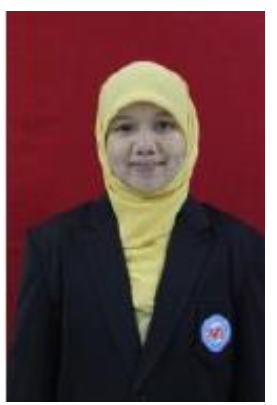

Entin Sutinah

Tahun 2009 lulus dari program starta satu (S1) program studi Sistem Informasi Manajemen STMIK Swadharma Jakarta, Tahun 2014 Lulus dari program starata dua (S2) program studi Ilmu Komputer STMIK Nusa Mandiri Jakarta. saat ini berkerja sebagai staff pengajar di Universitas Bina Sarana Informatika Fakultas Teknologi Informasi.

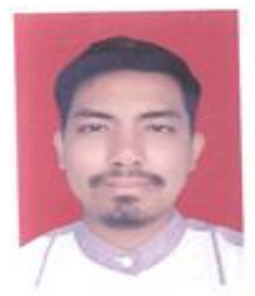

\section{Rizal Gustiar}

Lulus D3 tahun 2011 Jurusan Manajemen Informatika pada Universitas Bina Sarana Informatika, Tahun 2018 Jurusan Sistem Inforamasi pada STMIK Nusa Mandiri Jakarta 